\title{
Cuadro de costumbre: Vicente Grez, crítico de arte
}

\section{Essay of Manners: Vicente Grez as an Art Critic}

\author{
Alberto Madrid \\ Universidad de Playa Ancha \\ amadrid@upla.cl
}

\section{Resumen:}

Este estudio aborda la producción escritural de Vicente Grez relacionada con las bellas artes chilenas del siglo XIX. En el marco de una investigación sobre la crítica de arte en las artes visuales chilenas, la selección de obra de Grez tiene como contexto de recepción el taller, el Salón y su puesta en circulación en los medios de la época en una investigación en una interpretación fronteriza de las relaciones de las artes y la literatura, siendo uno de los primeros escritores chilenos que desarrolla la crítica de arte.

Palabras clave: crítica de arte, exposiciones, Antonio Smith, arte-literatura, siglo XIX.

\begin{abstract}
:
This study approaches the writings Vicente Grez related to Chilean Fine Arts of the 19th century. Within an investigation about art critics of Chilean visual arts, the works selected by Grez have their reception context in the studio, the Hall and its exposure in the press of the time; in a border interpretation of relations between Arts and Literature. Grez is one of the first Chilean writers who developed art criticism.
\end{abstract}

Keywords: Arts Critic, Expositions, Antonio Smith, Art-Literature, $19^{\text {Th }}$ Century. 


\section{Vicente Grez (1847-1909), periodista, escritor y crítico de arte}

Vicente Grez es un representante finisecular de la generación de 1882 correspondiente al periodo naturalista, según la clasificación de la Historia de la literatura chilena de Hugo Montes y Julio Orlandi. De igual modo, en 1968 Cedomil Goic en La novela chilena. Mitos degradados, lo ubica como representante del naturalismo. En la misma fecha, como editor, Raúl Silva Castro se hace cargo de la publicación La vida santiaguina, en la cual realiza una introducción biográfica en la que caracteriza su condición de crítico de arte; tal como indica:

Es hora de señalar, asimismo, que Grez llegó a ser especialista en la crítica de las bellas artes, lo que lo autorizaba para compartir, en calidad de secretario, la labor de la comisión encargada de organizar la presentación de Chile en la Exposición Universal de París de 1889, y escribir para ella, la primera obra de conjunto que se ofrece en la bibliografía chilena sobre la evolución de las artes plásticas, Les beaux arts au Chili, impresa por encargo oficial en París. De otra parte fue secretario de la Junta directiva de bellas artes desde 1883, y crítico oficial del salón oficial de pintura y escultura en diversas fechas y en diversos periódicos como El ferrocarril en la temporada de 1884 y 1885, en mayo de 1886 para los Debates, en 1887 para La Época, etc. (Grez, Como en Santiago 29-30).

La cita de Silva Castro sirve como telón de fondo para el estudio de Vicente Grez en su rol de crítico de arte, práctica periodística en ciernes si se tiene en consideración que en 1849 se inaugura la Academia de Pintura a cargo de la formación de los futuros pintores de historia.

La institucionalidad artística, en sus componentes de producción de obra, de circulación y recepción, será coincidente con la etapa de producción escritural de Grez. Cuando comienza a circular la obra de los primeros pintores formados en la Academia de Pintura, su instancia de visibilidad será en la exposición de 1872 organizada por Benjamín Vicuña Mackenna, siendo intendente de Santiago, en el marco de la inauguración del Mercado Central. Por cierto, Vicuña Mackenna es figura clave en los inicios de la constitución del circuito de arte; tanto él como Grez son representativos de los caballeros ilustrados pertenecientes a la élite social del país. En tal momento se da una alianza natural entre clase social y política en la preocupación por la construcción del gusto, aspecto importante a retener en el momento que escribe Grez sobre bellas artes.

Esta práctica comenzará a emerger en periódicos y revistas asignando un espacio que pone de manifiesto el proceso de profesionalización de los modelos escriturales; ya no solo se trata de crónicas o reseñas sino de críticas de arte:

Las nociones que hubo de asimilar Grez para la crítica de las bellas artes fueron más prácticas que teóricas, lo que explica, de otro lado, el efecto de sus comentarios, leídos por los artistas y apreciados en el acto en su preciso alcance, gracias a la limpidez y a la gracia de la forma. Y lo suponemos ante todo prácticas, porque quien se tome el cuidado de repasar las páginas de la Revista de Santiago, en sus publicaciones de 1872, encontrará dos bellos artículos que dan cuenta de las actividades de Grez (Grez, Como en Santiago 30). 
Es precisamente Raúl Silva Castro quien se ha ocupado de destacar el trabajo fronterizo de Grez en tanto crítico de arte proveniente del sistema literario que se desplaza a las bellas artes. Situación distinta a la de José Miguel Blanco quien, como artista, se hace cargo de un medio creado preferentemente para las bellas artes: El Taller Ilustrado, en 1885, desarrollando el ejercicio de la crítica de las bellas artes.

Si se pone atención a las fechas, es a fines de la década de los setenta y en los ochenta del siglo XIX en que se da la institucionalización de un sistema crítico profesionalizado. Ejercen la crítica en representación de la oficialidad Vicente Grez y Pedro Lira, quienes en algún momento van a coincidir en sus debates con José Miguel Blanco en bandos distintos; los primeros como representantes de la elite oligárquica ilustrada, en tanto el segundo de la meritocracia.

Este estudio se ocupará de los textos relacionados con las bellas artes que aparecen en la edición de 1968 de La vida santiaguina (se hace énfasis en la fecha, ya que en la primera edición de 1879 tenía otros textos). La publicación analizada incorpora los artículos "En el taller de Pedro Lira” y "Una visita artística. Nicanor Plaza”, publicados originalmente en 1872 en la Revista de Santiago y El Salón Nacional (1890). Se debe tener presente que el único texto relacionado con las bellas artes que aparece en la edición original de $\mathrm{La}$ vida santiaguina publicada en 1879 es "Lo que era el arte en Santiago (Una aventura en 1840)”. Además se revisará la monografía sobre Antonio Smith (Historia del paisaje en Chile) de 1882 y el libro Les beaux-arts au Chili de 1889 para la Exposición Universal de París en la fecha mencionada.

El corpus de textos seleccionado corresponde a diferentes regímenes textuales: crítica, crónica, monografía e historiografía, con lo cual se puede elaborar tanto un panorama de la escritura de Grez como de la crítica y de los inicios de la historiografía del arte chileno.

De la introducción biográfica que aparece en La vida santiaguina, se realiza una lectura parcial atendiendo al correlato de la crítica de arte. No es objeto de análisis en esta ocasión la producción literaria de Grez. El ensayo de Raúl Silva Castro tiene dos versiones: la primera como comentario para la publicación de 1968 de La vida santiaguina y, la segunda, en 1969 en el ensayo Vicente Grez (1847-1909), en los cuales el lector encontrará una detallada descripción e historia de la trayectoria de Vicente Grez, de acuerdo a un modelo de escritura propio de la historia de la literatura chilena.

La investigación en curso aborda la relación arte y literatura, reiterando el procedimiento de utilizar textos provenientes de la literatura para ser usados como fuente primaria para documentar las artes visuales chilenas ${ }^{1}$. De ahí la incorporación de "Lo que era el arte en Santiago (Una aventura en 1840)", que se encuentra en el capítulo VII de La vida santiaguina, que se puede considerar un artículo de costumbre.

1 En un artículo anterior se ha desarrollado inicialmente la relación arte y literatura "Cuadro de Historia. Jacinto Chacón Barey. Arte y literatura siglo XIX en Chile", como parte del proyecto Fondecyt "La construcción del gusto. La crítica de arte en Chile 1849-1970", cuyo investigador principal es Pedro Emilio Zamorano y coinvestigadores Claudio Cortéz y Alberto Madrid. 


\section{"Lo que era el arte en Santiago (una aventura en 1840)"}

El sujeto del enunciado relata una crónica sobre un personaje que se designa como $\mathrm{M}$. Adolfo G., de origen francés que llega a Santiago en 1839 o 1840. La imprecisión no es un dato menor en Grez, como se verá más adelante. La caracterización y acontecimientos en torno a M. Adolfo G., están referidos de acuerdo al léxico de la época a las bellas artes. Su indumentaria responde a la de un sujeto de gusto respecto del medio nacional. Complementa su condición el título nobiliario de conde:

Por otra parte M. Adolfo G. era un turista, viajaba por placer. Dueño de una gran fortuna, llevaba consigo colecciones artísticas, verdaderamente admirable. Venía a Chile para contemplar en toda su grandeza la cordillera de los Andes, subir hasta la cumbre del Tupungato o del Aconcagua y después regresar a Europa, y tal vez escribir de sus viajes (Grez, La vida santiaguina 122).

La precisa descripción no tiene desperdicio según los códigos de época, ya que en ese tiempo era característica la figura de los viajeros, pero a diferencia de M. Adolfo G., se debe considerar a los artistas viajeros o a los de las expediciones científicas. Por el modo como es presentado, responde casi a un dandy, más el detalle de la continuidad de la trama está en la colección con la que viajaba. Rápidamente M. Adolfo G. se transforma en un sujeto atractivo para la vida social de la provincia; quien, sintiendo la hospitalidad de los residentes, dejará el hotel:

[...] se instaló pronto en los altos de una casa que decoró con esplendor. Ricos tapices y cortinaje, muebles de una forma extraña, divanes otomanas, bules cargados de lindos juguetes, jarrones del Japón o de China, todo lo que anhela el confortable y acaricia la imaginación se veía ahí reunido. Las habitaciones de M. Adolfo G. eran verdaderos museos de arte. Las murallas estabas cubiertas de pintura al óleo, de buenos y malos autores, las buenas eran copias, las malas originales; veíanse también acuarelas, sepias, grabados, daguerrotipos, fotografías, dibujos a la pluma y al lápiz atribuidos a celebridades. Bronces que representaban a Fausto, solo o acompañado de Margarita; a Don Quijote solo o acompañado de Sancho; mármoles que simbolizaban dioses y ninfas; todo inmundo histórico y alegórico (Grez, La vida santiaguina 122).

Según la descripción del cronista, la ambientación se podría resumir como un cuadro de gabinete de curiosidades. Siguiendo el humor de este, la curiosidad de "un ojo inteligente habría descubierto que aquellos originales no eran tales" (Grez, La vida santiaguina 123). Ciertamente, con posterioridad en la trama, toda esa ilusión se desbarata, pero antes, $\mathrm{M}$. Adolfo G. inventa el hecho que debe volver a Francia por la muerte de un pariente que le ha heredado una cuantiosa fortuna por lo que decide poner sus obras en venta:

Los salones de M. Adolfo G. fueron abiertos al mundo elegante y la venta principió. En un solo día las habitaciones quedaron vacías. Todo se vendió a precio fabulosamente bajo; fue aquello una quemazón. Un Ticiano original se compró en setecientos pesos, 
un Rembrandt en quinientos, un cuadro de batalla de Horacio Vernet, que tenía el mérito de ser la tela más pequeña que había pintado ese artista, se vendió en ochocientos, y así sucesivamente. Un año más tarde Monvoisin veía algunos de estos cuadros y se asombraba de nuestra credibilidad. Los bronces y mármoles corrieron la misma suerte: una Venus, valor de tres francos fue vendida en setenta y cinco pesos; el famoso grupo de Fausto y Margarita, que su dueño había comprado en ochenta francos, fue vendido en seiscientos pesos (Grez, La vida santiaguina 123).

La crónica en la constelación de los otros textos de La vida santiaguina responde a un cuadro de costumbres, en el sentido de que describe un tipo de sociabilidad que es simbolizada en un momento de transición, distanciándose del legado colonial y abriéndose al mundo siguiendo el modelo europeo, pero imitándolo y reproduciéndolo en la mala copia, como lo deja de manifiesto el texto analizado. El relato se interrumpe con observaciones sociológicas como el surgimiento de un nuevo gusto por la apariencia de lo importado, específicamente por objetos de origen francés.

Antes mencioné, y en el tono aparentemente anecdótico de la crónica, un problema que es recurrente en la historiografía del arte chileno: su falta de precisión en la datación de las fechas. Cierto es que se puede dejar pasar la ambigüedad al inicio de la crónica, "En 1839 o 1840 llegó a Santiago", pero ello conduce a error en la trama de los acontecimientos cuando se indica que "Un año más tarde Monvoisin veía alguno de estos cuadros y se asombraba de nuestra credulidad" (Grez, La vida santiaguina 122). De acuerdo a fuentes revisadas, Monviosin llega a Chile en 1843 (si bien en textos del periodo lo consignan en $1845^{2}$ ).

En "Lo que era Santiago (Una aventura en 1840)", el cronista pone de manifiesto la falta de conocimiento del arte por parte de la sociedad chilena, aunque a la fecha ya circulaban artistas viajeros como Charles Wood, Mary Graham, Mauricio Rugendas, entre otros. ¿Cuál era el estado del conocimiento del arte antes del engaño de la venta de la supuesta colección de M. Adolfo G.? Preferentemente pintura colonial residual traída de los talleres de Quito y de la primera retratística de la clase dirigente realizada por el Mulato Gil de Castro. El alcance a Monvoisin no es casual en la crónica, dado que si se reconstruye el horizonte de expectativas, la llegada del artista marca un hito para las bellas artes según algunos, entre ellos Grez, además de Lira. En un comienzo, Monvoisin es invitado al país para hacerse cargo del proyecto de la Academia de Pintura, pero por falta de acuerdo en su remuneración con el gobierno abrirá su propio taller para dedicarse al retrato y sus ingresos serían más significativos.

En otro texto de Grez sobre Antonio Smith, comenta en tono anecdótico que Monvoisin llega al extremo del mundo por un mal de amor, que al igual que el personaje

2 Cfr. Lira, Pedro. "Las Bellas Artes en Chile". Anales de la Universidad de Chile XXVIII (1866). 276-92. Medio impreso. También Urquieta, Luis Álvarez. La pintura en Chile, Santiago: Imprenta La Ilustración, 1928. Medio impreso. 
de la crónica, "se dejaba comprender fácilmente que ese hombre más bien que por amor a la naturaleza viajaba por curarse de una pasión desgraciada" (Grez, Antonio Smith 22):

En todo caso no deja de sorprender el imaginar para la época lo que debía ser en términos de traslado de equipaje la colección que se comenta de M. Adolfo G. De ahí que su montaje y exhibición debe haber sido todo un acontecimiento para los habitantes, puesto que cuando se observan grabados de época, los salones, mobiliario y ornamentación son bastante austeros y con escasas colecciones. “Todos estos adornos, todos esos dijes de la industria francesa, hoy abundantes, eran entonces escasos en Santiago. Los grandes salones solo se decoraban con espejos" (Grez, Como en Santiago 122).

Tal como se ha mencionado anteriormente, tres décadas después de la fecha en que se inscriben los acontecimientos descritos en La vida santiaguina, que se publica en 1879, otras eran las características del campo simbólico. Ya se habían creado las instituciones educativas y las condiciones para el fomento del gusto. En este contexto es que ya circulan los discursos que se distancian de la anécdota de la crónica por modalidades textuales de mayor densidad, como la profesionalización de la prensa. El propio Grez irá modificando su escritura, cuya evolución da cuenta de los cambios de los formatos de la mediación de la prensa.

Para el análisis de su evolución, el estudio continúa con la selección de tres modelos o prácticas escriturales de Vicente Grez en su condición de crítico de arte. El primer modelo refiere a tres textos que circulan en revistas de la época: "En el taller de Pedro Lira", "Una visita artística. Nicanor Plaza", ambos publicados en 1872 en la Revista de Santiago, y "El Salón de 1890" en la Revista de Bellas Artes; el segundo modelo corresponde a la monografía sobre Antonio Smith (Historia del paisaje en Chile) de 1882; y el tercero a Les beux-arts aux Chili de 1889, textos que se inscriben en casi dos décadas de circulación para diferentes instancias de recepción.

Los primeros textos publicados dan cuenta de la evolución escritural de Grez; aquellos aparecidos en la Revista de Santiago se caracterizan por ser de difusión y forman parte de la construcción del gusto y de acercamiento con un público que no posee el conocimiento de las bellas artes. Por ello recurre a la crónica laudatoria y a la reconstrucción de la biografía. La selección de los artistas responde al canon que va elaborando Grez y su valoración.

\section{En el taller de Pedro Lira}

A partir del taller del artista trata de acercar al espectador-lector al espacio de la creación, a la figura del artista y la materialidad, incorporando sus categorías de análisis. Grez se acerca a la obra de Pedro Lira en su momento de formación, periodo en que él debe resolver la exigencia familiar de una carrera tradicional, por lo cual para cumplir con el padre se titula de abogado, siendo su vocación la pintura. Este es un aspecto caracterís- 
tico en relación a la imagen del artista con su clase social su origen: ver la condición del artista como algo poco útil. La descripción de Grez contextualiza la formación de Lira en la cercanía con la de otro artista que se ha ocupado: Antonio Smith. Paralelamente con asistir a la academia, Lira completa su formación en el taller de este:

\begin{abstract}
Una corriente misteriosa de simpatía ligaba a Lira con el fundador de nuestra escuela de paisaje y con todo ese pequeño y cariñoso grupo de gente de taller y paleta que forma nuestra esperanza y nuestro orgullo artístico. En medio de esos bellos trabajos, de esos debates diarios y de esa crítica constante sobre las bellas artes, fue tal vez donde Pedro Lira encontró y desarrolló su afición a la pintura (Grez, Como en Santiago 140).
\end{abstract}

La imagen del taller que comunica Grez, responde no solo al lugar del aprendizaje sino a lo que sucede al interior de este con la afección de la formación que se traduce en la conversación y el ejercicio de la mirada.

Grez describe el ambiente inicial de la formación de Lira, no como la del patriarca de las bellas artes, de la figura finisecular consagrada, sino la del momento del hallazgo. Su atención es en unas pinturas de paisaje que no le son propias, dado que Lira responde más al modelo de la academia del pintor de historia, si bien practica todos los géneros. Refiriéndose a uno de sus cuadros Grez señalará:

Es en este último cuadro donde se nota sobre todo un progreso evidente y una intención vigorosa en la ejecución y en la idea. Las incertidumbres y las vacilaciones del artista, que tan remarcables aparecen en sus primeros cuadros, se disipan aquí ante la verdad de la naturaleza que pinta. Es en este paisaje donde principia a diseñarse una personalidad y un propósito: según parece comprenderlo Lira, no solo tiene por objeto representar lo bello, como pensaban los antiguos, sino ante todo la verdad de la naturaleza (Grez, Como en Santiago 148).

En la secuencia del análisis de Grez, se puede apreciar el acercamiento biográfico, el temático y, en un tercer momento, la atención a la naturaleza de la formación y práctica artística, lo que le permite estructurar los códigos para desarrollar sus categorías de análisis: ejecución, composición, colorido, influencia, talento, las que utilizará en la descripción y valorización de las obras:

Hemos notado que Lira prefiere siempre para sus composiciones los aspectos de montañas, en los cuales nuestra imaginación se reviste de un tono más tierno y severo. Es ésa por otra parte una inclinación natural en un artista que estudia día a día la naturaleza montañosa de su patria (Grez, Como en Santiago 143).

El cruce de observaciones del artista y el crítico en relación a la naturaleza van sentando los elementos de la construcción de un imaginario nacional donde el paisaje será un factor constitutivo de la identidad. No se debe olvidar que en la base de ello está la idea de la representación de lo nacional a través del territorio. 
Cierra la revisión de Grez sobre Pedro Lira en el momento que este está pronto a seguir su formación en Europa y a modo de síntesis realiza su valoración:

Los que han seguido paso a paso los progresos de Lira no podrán menos de admirarse en presencia de su último paisaje de la rápida jornada que ha hecho. Pintar así cuando no hace todavía dos años tomó el pincel por primera vez, es marchar bien apresuradamente a un porvenir seguro, a un destino brillante.¿A dónde no llegará después de los cinco o seis años de estudios que proyecta hacer en Italia? Los que amamos la gloria artística de Chile deseamos que así suceda y confiamos que así sucederá (Grez, Como en Santiago 143-4).

La cercanía entre Grez y Lira descrita en este pasaje es un capítulo más en los que más adelante coincidirán los personajes en diversas gestiones asociadas con las bellas artes de fines del siglo XIX.

\section{"Una visita artística. Nicanor Plaza"}

En el artículo "Una visita artística. Nicanor Plaza", Grez se detiene en la ambientación del taller del artista:

Nada más encantador que el desorden que ahí domina. Un diván, una cuantas butacas, pocos libros pero muchos grabados, paisajes, retratos, marcos esperando una tela o trozos de mármol esperando el cincel inspirado del artista para convertirse en forma encantadora e inmortal; todo cubierto con un poco de polvo desdeñoso que explica la indolencia de su dueño (Grez, Como en Santiago 145).

Grez visita el taller de Plaza en 1872, fecha en la que Benjamín Vicuña Mackenna ha organizado la exposición del Mercado, como se la designa, que coincide con su inauguración y la obtención de Plaza de la Medalla de Oro. A diferencia del artículo antes reseñado en que Lira está en proceso de formación, Plaza se encuentra en su plenitud creadora y es considerado el primer estatuario del país.

A continuación Grez se dedicará a comentar algunas de las obras de Nicanor Plaza, analizando cinco: Bacante, Eva, Caupolicán, El jugador de chueca y Amor cautivo. Previo a entrar en el recorrido de las obras, contextualiza la situación de la escultura cuya mayor referencia en el país, según Grez, es la pila de la Plaza de Armas. También destaca el momento de la producción y su circulación, "pues hemos llegado felizmente a un grado tal de progreso artístico, que obra terminada es obra salida del taller y muchas veces disputada con entusiasmo" (Grez, Como en Santiago 147).

Una de las obras en las que se detiene Grez es la que designa como Eva, donde interesa destacar el modo como la describe:

Eva aparece en ese momento de súbita y terrible revelación que es natural tuviera después de su dulce condescendencia. Su cabeza parece todavía envuelta en una nube de 
incertidumbre y de dudas; y su mano, levantada a la altura de su frente, parece querer dulcificar los rayos de una verdad que hieren su vista. El momento elegido y la actitud vagarosa de la pecadora son bellísimos.

La primera mujer debe haber sido también la más bella; así parece haberlo comprendido el artista, y el cuerpo de Eva es de una gracia y perfección admirables. Todas sus líneas tienen una suavidad y pureza delirantes, y si algo pudiera criticarse sería tal vez el sentimiento un tanto mundano que despiertan (Grez, Como en Santiago 148).

La descripción que hace de la obra Vicente Grez llama la atención en uno de sus gestos: "y su mano levantada a la altura de su frente", dado que no corresponde al de la obra analizada. Para esclarecer, se ha recurrido a la consulta de documentación considerando tres fuentes primarias: "El arte nacional i su estadística ante la Exposición de 1884" (Revista Retrospectiva), 1858-1884, de Benjamín Vicuña Mackenna; "Exposiciones de arte en Santiago 1843-1887” de Hernán Rodríguez Villegas y “Gestación de la escultura en Chile y la figura de Nicanor Plaza" de Pedro Emilio Zamorano.

De las cinco obras que Grez describe en el taller de Plaza, cuatro se encuentran en la exposición de 1872, organizada por Benjamín Vicuña Mackenna:

Su Caupolicán, que seguirá siendo su obra maestra emigró entonces al parque de Lota y su Jugador de chueca al parque de Panquehue, al paso de su deliciosa Bacante, como avergonzada de su eterna embriaguez ha ido a refujiarse en una quinta del Camino de Cintura y su púdica Susana, sorprendida por los lascivos viejos, ha corrido a esconderse no sabemos ¿dónde? a un taller de vestir santos talvez (Vicuña Mackenna 425).

En tanto en el análisis de la misma exposición, Rodríguez señala: “y de las esculturas de Nicanor Plaza cuya desnuda Susana causo polémica con El Estandarte Católico y produjo un escándalo que significa mayor afluencia de público curioso" (Rodríguez 303).

La publicación más reciente sobre la obra de Plaza es de Pedro Zamorano y corresponde a un estudio del contexto de producción de su obra y el catálogo razonado. La obra analizada se consigna como Susana saliendo del baño, de 1870, que en la actualidad se encuentra emplazada en medio de la piscina de un regimiento en Coquimbo, en la cuarta región ${ }^{3}$.

Según las fuentes consultadas, la obra que Grez describe y nombra como Eva sería Susana saliendo del baño, ya que además por su descripción el gesto no corresponde con la obra antes mencionada; en esta, la mano derecha cubre el seno izquierdo y la otra mano se apoya en una especie de pedestal donde se aprecia un paño. También se ratifica la comparación con el texto de Grez cuando indica "y si algo pudiera criticarse sería tal vez el sentimiento un tanto mundano que despiertan" (Como en Santiago 138) lo que es corroborado en la versión de Rodríguez cuando se refiere al impacto que causó y la

3 Zamorano, Pedro. Gestación de la escultura en Chile y la figura de Nicanor Plaza. Santiago: Ediciones Artespacio, 2012. 
reacción del periódico clerical y conservador de la época El Estandarte Católico. Con más humor, Vicuña Mackenna indica que no sabe dónde ha ido a esconderse. De igual modo, al revisar el catálogo razonado, documentado por Zamorano, no se encuentra ninguna obra de Plaza con el título Eva y tampoco aparece la quinta obra mencionada por Grez: Amor cautivo. Ello pone de manifiesto una vez más las dificultades de documentación de las artes visuales chilenas. Más adelante la percepción de Grez es coincidente con la de Vicuña Mackenna en relación a la obra Caupolicán como una de las más representativas y reconocidas de Plaza de la que existen siete ejemplares en distintas ciudades del país.

En términos de un modelo de referencias de la crítica de arte de Grez en "Una visita artística. Nicanor Plaza” es más notoria su vinculación con su procedencia literaria, en el sentido de que lo dominante en la descripción de obra es el relato por sobre la forma, si bien le interesa destacar la ejecución del dibujo. En el caso de la escultura será la idea respecto de su materialización y simbolización en lo que se detiene el crítico:

Por eso, lo repetimos, si algo pudiera criticarse a la hermosa obra de Plaza, sería tal vez la falta de acentuación más marcada de poesía y sublimidad en su rostro. Es un error creer que hay más verdad en la ciencia del arte. La poesía es la expresión de una idea, y por esto mismo está más cerca de la verdad que la ciencia, que toma siempre su punto de partida de hechos variables o fugitivos. La generalidad no comprende o no conoce las leyes científicas del arte; pero si puede percibir los signos de la armonía sensibles a la vista del más profano, y cuando esa armonía le seduce y toca las fibras más delicadas de su espíritu, proclama bella y magnifica la obra de arte que tiene delante de su vista (Grez, Como en Santiago 148).

El juicio de Grez es semejante a la valoración que hace de la mencionada obra Eva en la que se destaca una lectura de carácter alegórica; mediante la percepción del objeto se establecen relaciones en la dialéctica de la ejecución de la idea y sus connotaciones.

\section{El Salón (1890)}

También es parte de los artículos de arte seleccionados en La vida santiaguina, la crítica de Grez sobre el Salón Nacional de 1890, publicada en diciembre de 1890 en la Revista de Bellas Artes. Aquí es la figura del crítico recorriendo el Salón. Si antes fue el taller, ahora es la exposición anual la que permite formarse un panorama del desarrollo del arte. El texto está dividido en tres partes: la primera es la visión general, la segunda la detención en la pintura y la tercera en la escultura.

La mirada del crítico en relación al Salón es la de un balance en la que emite una valoración desde la información que dispone, como antecedente con el que evalúa el avance de los artistas de quienes se ocupa; lo anterior le permite ir estableciendo el canon de la época. Tal como indica Grez: 


\begin{abstract}
Más numeroso por la cantidad de las obras exhibidas así como por la de los artistas que a él han concurrido, el Salón de 1890 es también superior al del año pasado por el mérito de las producciones que lo constituyen. No es está la opinión de la crítica en general, que estima la actual exposición inferior a las dos anteriores (Grez, Como en Santiago 172)
\end{abstract}

Sin embargo, en el estudio de las obras se contradice, reconociendo que la mayor parte de los artistas exponentes ha realizado durante el año un progreso muy considerable.

Si se tiene presente que los textos antes comentados son de 1872 y ahora se está frente a uno del Salón de 1890, ha pasado más de una década. En este tiempo han ocurrido acontecimientos significativos en el sistema de las bellas artes, tanto en la emergencia de nuevos nombres de artistas y medios de prensa como en la circulación de obras. Con respecto a lo último se debe tener en consideración la Exposición Internacional de 1875, la Exposición de 1884 y la participación del envío de la Exposición Internacional de la Feria Universal de París de 1889, cuyo comisario fue Grez. Paralelamente, en aquellas últimas décadas la difusión se ha ampliado en las escrituras y la recepción de las plumas de Benjamín Vicuña Mackenna, Pedro Lira, José Miguel Blanco, Pedro Balmaceda, además de Grez. Existe consenso entre estos que desde mediados de la década de los ochenta se está en presencia de todos los componentes que caracterizan a un sistema de arte.

En el escenario descrito ciertos artistas ya están en su madurez, tales como Lira, Jarpa, Guzmán, Correa, Celia Castro y los nuevos Daniel Tobar, Alfredo Castro. En el caso de la escultura Plaza, Blanco, Arias y los nuevos Concha, Tapia, Lagarrigue.

El modelo de crítica de Grez respecto del sistema de análisis de un salón pondrá atención en la ejecución, en lo temático, la composición, la línea, el color, categorías que son propias de la academia que es lo imperante de la valoración de las bellas artes a fines del siglo XIX en el país.

\title{
Antonio Smith (Historia del paisaje chileno)
}

Otro modelo escritural de Grez corresponde a la monografía sobre Antonio Smith de 1882. En esta ocasión se hace cargo de la biografía del pintor Smith y su contextualización, que le permite desarrollar un panorama y evolución de las bellas artes. Smith es de los primeros en integrarse a la Academia de Pintura y desertar de ella. La revisión de Grez da cuenta de dos décadas.

La complicidad entre el sujeto de los acontecimientos y quien los describe se establece en la semejanza de caracteres coincidiendo en el humor y en la locuacidad. En la analogía del retrato con el relato partiré por el final del texto de Grez para hacer una lectura en reversa, ya que este cita un texto anterior a modo de relato incrustado, donde comenta que está junto a un Smith convaleciente, dejándolo para no fatigarlo. Luego en la tarde se 
entera de su muerte. "Un amigo, un artista, Nicanor Plaza, se preparaba a extender una capa de yeso sobre el rostro del difunto para sacar su máscara” (Grez, Antonio Smith 83).

La selección del texto no es casual si se tiene en consideración la acción de Plaza que reproduce el momento de construcción de una imagen, la que es fijada desde el modelo original para transferir su representación. Por su parte el gesto de Grez es semejante en la descripción con las palabras. Sacar una máscara es atender a la singularidad de la persona. Aquí la metáfora de la máscara es en oposición al no ser conocido.

La monografía de Grez sobre Smith se estructura desde la fisionomía, la genealogía, el entorno cultural, la formación, la producción artística y su valoración que son abordados en los veintiocho apartados del texto.

Grez elabora la imagen de Antonio Smith como el artista bohemio de espíritu romántico que plantea una contradicción entre sus motivaciones y lo que de él espera su familia. Lo que Grez ilustra con algunas anécdotas del personaje que construye:

Su abuela, la señora Trucios, no podía conformarse con que su nieto abrazara una profesión que para ella era casi la de un humilde obrero. La orgullosa dama inició las hostilidades despedazando las telas, las paletas, los pinceles i las pinturas del artista, $\mathrm{i}$ como si hubiera temido que esos trozos pudieran juntarse nuevamente los arrojó en un resumidero (Grez, Antonio Smith 16-7).

Como suele suceder, la acción de la abuela reforzará en Smith su vocación artística distanciándose del deseo y modelo familiar de una carrera de abogado (recuérdese antes lo sucedido con Pedro Lira, la exigencia del mismo modelo). Luego Grez se detiene en el cuadro de época cuyo espacio cultural lo resume en el Instituto Nacional, que viene a ser el cuadro de honor de la intelectualidad naciente del Estado que se proyecta a través de sus instituciones educacionales como expresión del progreso:

El Instituto Nacional estaba en todo su auge. Lastarria, Varas, Courselle, Seneuil, Gorbea, Sazié, García Reyes, Solar, Vendel-Heyl, Gümes eran nuestros maestros. Con semejantes conductores la juventud marchaba hacia un ideal de justicia y libertad... (Grez, Antonio Smith 19-20).

En este mismo contexto, el gusto por las bellas artes era parte de los ideales que se les ofrecía a los jóvenes. En los apartados que van del cuatro al ocho Grez desarrolla los antecedentes de las bellas artes en el país, sin ser una construcción lineal y evolutiva, sino que a través de instantáneas va estableciendo los hitos de la historiografía del arte chileno. Grez publica el ensayo de Smith en 1882; la Academia de Pintura lleva funcionado treintaitrés años y en este tiempo ha contado con dos directores: Alejandro Cicarelli por dos décadas y a continuación, desde 1870, Ernesto Kirchbach. Tanto Grez como Lira establecen como inicio de las bellas artes la llegada de Raymond Monvoisin (si bien equivocan su datación indicando 1845, siendo lo correcto en 1843), en quien se había pensado inicialmente para hacerse cargo de la Academia. De igual modo, ambos también tienen una valoración negativa de Cicarelli tanto de su obra como de la enseñanza. 
Propio de la discursividad de Grez es el componente anecdótico que se manifiesta en relación a las motivaciones de la llegada de Monvoisin:

Ni era posible creer que este artista eminente, quisiera cambiar su brillante posición de jefe de la Escuela Francesa de Roma, por la vaga promesa de venir a dirigir una oscura escuela de pintores en el extremo de un mundo todavía desconocido. Su viaje a Chile tuvo por causa, como lo repetía la chismografía de la época y desgraciadas aventuras de amor, en la que teniendo por rival, y rival afortunado, al conocido novelista M. Paul de Kock, cruel hasta el exceso, había ridiculizado a su rival en una novela titulada Monvoisin Raymond, cuyo protagonista no era otro que Raymond Monvoisin (Grez, Antonio Smith 23-4).

Si bien Monvoisin no forma escuela, colaboró en la enseñanza del amor por lo bello. Un género desarrollado, preferentemente, en su producción artística fue el del retrato. Se considera como sus discípulos a Francisco Mandiola y a los argentinos Gregorio Torres y doña Procesa Sarmiento, esta última, hermana de Domingo Faustino Sarmiento quien en ese momento se encontraba exiliado en Chile y desarrollaba una importante labor educativa y también ejercía la crítica en la prensa de la época.

Luego Grez reproduce mediante la cita del diario El Progreso la inauguración de la Academia de Pintura y parte de los versos de Jacinto Chacón, poeta representante de la generación de 1842, quien recepciona el discurso de Cicarelli. Para completar la información describe (en el apartado siete) los cursos de la Academia.

La carrera artística aparecía como una novedad para los jóvenes en un país sin tradición por lo bello; ella venía a contribuir a la construcción del gusto. Será Smith uno de los alumnos sobresalientes. También Grez reitera su juicio negativo sobre Cicarelli:

Pronto, sin embargo, la flamante Academia principió a levantarse, surgiendo de entre sus compactas filas una que otra esperanza. Cicarelli a pesar de su carácter lleno de rarezas, burlón y solemne, a la vez, era empeñoso y leal, y estimaba como un triunfo personal, que le inundaba de noble júbilo todo destello de inteligencia que descubría en sus alumnos (Grez, Antonio Smith 30).

Entre ellos estará Smith, pero con el tiempo se distancia porque su emotividad no se ajustaba con el modelo de la exigencia académica; la abandona y se incorpora a la carrera militar, de la que, con su humor, Grez dice que de igual modo podría haberlo hecho con la clerical. Su estadía en el sur, lugar de su regimiento, potencia su cercanía con la naturaleza e imaginación, imágenes que posteriormente estarán presentes en sus paisajes.

Smith deja la carrera militar, como alude Grez, en los tiempos de pacificación que vive el país; su espada sin uso se empezó a enmohecer por lo cual la cambió por el lápiz. En 1858, se incorpora en El Correo Literario como caricaturista: "La caricatura de Smith no era notable por el dibujo, al contrario, esta se resentía de la falta de escuela, sino por la gracia y la idea, por el juicio rápido que daba de los hombres, por la inventiva sencilla y natural con que los caracterizaba" (Grez, Antonio Smith 56). 
Circunstancias políticas cierran El Correo Literario. Posteriormente Smith se va a Europa a continuar su formación artística: “[...]y se dirigió a Florencia, en cuya ciudad vivió un año, visitando casi diariamente el taller de Carlos Markó, el gran paisajista romántico de la moderna escuela italiana" (Valdés 5).

La cita marca dos descalces: la Academia y el romanticismo de Smith. También abre otra vertiente de influjo, por usar una noción de época, la de la transferencia italiana en la formación de algunos artistas chilenos que a veces queda opacada por la hegemonía de la francesa.

Cuando Smith regresa a Chile en 1863, Cicarelli lleva catorce años a cargo de la enseñanza en la Academia. Según Grez nada significativo había pasado en ese periodo.

Smith instala su taller cercano a la Academia transformándose en una segunda academia, la del aprendizaje del paisaje. Asistieron a esta Lira, Cosme San Martín, Orrego, Alfredo Valenzuela, entre otros. Para Grez el discípulo por excelencia es Onofre Jarpa.

En los apartados que van del quince al dieciocho Grez realiza una lectura de obra confrontando criterios con otros críticos. El regreso de Europa de Smith coincide con el reconocimiento de su obra, lo que se manifiesta en los premios que obtiene en las exposiciones más importantes, como la Nacional de 1872 con la inauguración del Mercado, donde Smith, Nicanor Plaza y Manuel Antonio Caro son los artistas más significativos, y luego, en la Exposición Internacional de 1875 con la obra Puesta de sol en los Andes. A propósito señala Grez:

Esta rapidez en la ejecución esplica la naturaleza de su arte, que no era resultado del estudio profundo sino de las inspiraciones de su propio ser. Su pincel no se detenía a estudiar el carácter de la montaña o de una roca, sino que recogía los sonidos, los colores, las luces, las armonías, todos los caprichos fugaces de la naturaleza, dándoles formas tan tiernas i espresivas que el alma se conmovía contemplándolas (Grez, Antonio Smith 72).

La transformación que introduce Smith en la concepción del paisaje es el paso desde el fondo de la historia a la descripción y la subjetivización de la mirada. La materialización de la percepción del paisaje en Smith pasa por la experiencia in situ y en el taller.

Para la valoración de su obra, Grez introduce una variante sobre la traducción o la transposición de la relación de la pintura y poesía (tópico de larga tradición desde la poética de Horacio y sus resignificaciones): “A sus más bellas composiciones le faltan las últimas pinceladas maestras, rara vez es su obra completa. Sus cuadros son asunto a poemas; pero no son poemas" (Grez Antonio Smith 73).

Por lo inacabado de sus pinturas también más adelante se criticará a Juan Francisco González, quien por cierto es otro referente de la pintura de paisaje en el sistema del arte chileno.

Parte final del ensayo son los gestos laudatorios del biógrafo, destacando la dimensión humana del artista, caracterizado como despreocupado, contribuyendo al mito del bohemio. En todo caso según Grez: "tenía lo que nadie tiene hoy i lo que se hace más raro cada 
día, esto es, un profundo desprecio por el dinero: amaba más el ruido de un aplauso que el que pudiera hacer el ora del mundo cayendo en una cascada" (Grez, Antonio Smith 79).

La biografía de Grez sobre Smith se transforma en un antecedente para los estudios que desarrollará Antonio Romera quien incorpora la constante del paisaje en la pintura chilena. De igual modo Grez deja en evidencia que su visión sobre el ejercicio de la crítica está en su carácter fronterizo desde la literatura, ya que parte del sistema escritural y de referencias proviene de esta.

\section{Les beaux-arts au Chili}

El último texto en revisión de Vicente Grez corresponde al Les beaux-arts au Chili ${ }^{4}$ (Las bellas artes en Chile), libro producido para la Exposición Universal de París de 1889. En este resume una mirada de cuarenta años de las bellas artes chilenas del siglo XIX, en el cual revisa y analiza en su condición de crítico y comisario del envío chileno. El texto está dividido en ocho apartados y editado en francés. A diferencia de la actualidad, en la que los catálogos se presentan en una edición bilingüe, en ese momento se debe entender que el canon era el modelo francés, que Chile reproducía en las instituciones y el gusto.

Una lectura a través de sus apartados permite formarse una visión finisecular del desarrollo de las bellas artes en Chile. Grez parte desde la constatación afirmativa del estado de la institucionalidad artística señalando que "causará el asombro de cualquier espectador atento". Con ello quiere llamar la atención a que en los últimos años se han fundado "Las escuelas de Bellas Artes, se ha abierto el Museo, se han establecido las exposiciones periódicas, se está formando una biblioteca de arte, se levanta un monumento para las exposiciones" (Grez, Les beaux-arts au Chili).

Es decir, están todos los elementos para facilitar la formación del gusto y el momento que vive el país es característico de una nación civilizada. En otra asociación, cuarenta años antes, en referencia a la fecha de fundación de la Academia de Pintura, Cicarelli en su discurso de inauguración vaticinaba sobre Chile: "me inclino a profetizar que este hermoso país será un día la Atenas de la América del Sur" (Cicarrelli 16). El alcance, además, a Cicarelli es por la semejanza existente con respecto al modelo escritural de Grez, dado que para el análisis, principalmente, se preocupará por la evolución de la arquitectura, para luego pasar a otras prácticas artísticas como la escultura y la pintura. Cierra el primer apartado especificando la finalidad de su análisis: "Nuestro objetivo en este estudio es dar cuenta brevemente de la historia del arte nacional" (Grez, Les beaux-arts au Chili).

Para cumplir con su objetivo utiliza como referencia los escritos de Miguel Luis Amunátegui y de Pedro Lira. Los textos a que hace alusión son: "Apuntes sobre lo que han sido las Bellas Artes en Chile" de Miguel Luis Amunátegui, publicado en abril de 1849 en

4 Este documento no tiene número de páginas. 
Revista de Santiago (la fecha que indica Grez es de 1848, con esto se reitera los primeros errores de datación en la historiografía del arte chileno); y "Las Bellas Artes en Chile" de Pedro Lira, publicado en 1866 en los Anales de la Universidad de Chile.

En el segundo apartado se detendrá en el catastro de las principales obras de arquitectura, lo que se puede considerar como metáfora de la edificación de la institucionalidad del Estado en el proyecto de nación. En el caso de la pintura y la escultura data los antecedentes en el período Colonial, indicando el aporte de los Jesuitas. Sus comentarios funcionan casi como instantáneas. A modo de ejemplo, "En cuanto a la escultura y pintura, la raza indígena no tenía hasta entonces una aptitud bien definida para cultivar ambas disciplinas" (Grez, Les beaux-arts au Chili).

De ahí que en su relato historiográfico considere el inicio del arte nacional desde el periodo colonial, si bien la producción local es una réplica de la imaginería producida en Quito, de la cual eran abastecidos los espacios religiosos. La época republicana estará representada por la retratística de José Gil de Castro.

Grez reiterará la mala datación en el tercer apartado al consignar en "1845 la llegada de un pintor francés distinguido”, aludiendo a Raymond Monvoisin quien llega a Chile en 1843 invitado por el Gobierno de Chile para hacerse cargo de la futura Academia, pero por desacuerdos económicos el proyecto no prospera y Monvoisin instala su taller particular dedicándose a la retratística de la oligarquía.

Aquí como en otros escritos, Grez manifiesta su valoración positiva de Monvoisin en desmedro de Cicarelli, quien se hace cargo de la fundación de la Academia de Pintura y la formación de los futuros artistas nacionales durante veinte años. Según Grez la llegada de Monvoisin marca un hito para las bellas artes en el país, si bien en el periodo ya circulan otros artistas como Charles Wood y Mauricio Rugendas. Este apartado funciona de bisagra para el quinto, donde establece lo que se podría considerar el canon de la época en que reconstruye momentos de la biografía de Monvoisin y el efecto de su presencia. "Monvoisin ha sido el pintor más distinguido que haya realizado una estadía de muchos años en Chile". Por cierto, la biografía de Monvoisin da para una novela. Continuará Grez con la descripción de la formación de Monvoisin y las referencias de su obra respecto de otros artistas franceses y Cicarelli, donde Grez reitera sus apreciaciones negativas sobre este último.

En el sexto apartado contextualiza la historia de la Academia, sus directores y los pintores formados por estos. También realizará una descripción y evolución de las principales exposiciones. Destacará el aporte de los directores Cicarelli, Kirchbach y Mochi.

De igual modo deja de manifiesto su aparato crítico, cuyo modelo es la Academia. En sus análisis destaca la identificación del género, destacándose la pintura de historia; luego buscará las influencias y los elementos de interpretación del cuadro, que serán el dibujo, el color, la composición y, como figura genérica de caracterización del artista, el talento.

Si con anterioridad registró como relevante la exposición de Monvoisin (1843), sigue su recuento a partir de 1861 destacando el papel de Pedro Lira y Luis Dávila en la 
formación de la Sociedad Artística en 1867 y, más adelante, la Exposición de 1884. Parte de las actividades de La Unión Artística será la construcción del Partenón (1885) de la Quinta Normal, espacio expositivo que posteriormente a partir de 1887 dependerá del Estado, transformándose en el edificio del Museo que desde 1880 ocupó diferentes oficinas de la repartición pública. Lo característico del periodo es la alianza del Estado con la oligarquía ilustrada, lo que revelaba, en el fondo, una sola instancia.

Una de las exposiciones más significativas que consideran Grez y los críticos de la época es la de 1872, organizada por Benjamín Vicuña Mackenna y llamada del Mercado, ya que coincide con su inauguración, en la que se visibilizan como los artistas más importantes a Nicanor Plaza, Manuel Antonio Caro y Antonio Smith.

El grado de progreso y el deseo civilizador se va a materializar con la Exposición Internacional de 1875, para lo cual en la Quinta Normal se edifica y habilitan los espacios adecuados. En la ocasión se editó un medio de prensa especial El Correo de la Exposición.

También Grez reproduce en este apartado el seguimiento que ha ido realizando de los artistas más representativos del período: Pedro Lira, Aurora Mira, Rafael Correa, Nicanor González, Alberto Orrego, Ramón Subercaseux, Onofré Jarpa, Juan de Dios Vargas, Enrique Swimburn, Juan Francisco González, entre otros. Por cierto que a Pedro Lira le dedicará parte importante de sus apreciaciones, situándolo como el gran artista del periodo.

En el séptimo apartado Grez completa la información que ha desarrollado sobre el incipiente coleccionismo en el país y documenta a los artistas pensionados a Europa para perfeccionar su formación artística. De los coleccionistas destaca a Luis Cousiño, Maximiliano Errázuriz, Florencio Blanco, entre otros, además de coleccionistas que financian dos importantes certámenes que llevan sus nombres: concurso General Maturana (Carlos) y Arturo Edwards. En el listado de las obras que adjunta predominan la escuela francesa, seguida de la española, italiana y, en menor representación, la belga y la inglesa. Esta fue publicada en el diario del Salón de la Exposición del año 1885. Lo anterior permite formarse una visión del gusto de la oligarquía por obras adquiridas en estadías y viajes a Europa.

Tal como se ha señalado, se incorpora la lista de los pensionados enviados por el gobierno y quienes viajaron con sus propios medios; de los primeros, Manuel Aldunate en arquitectura; Nicanor Plaza, José Miguel Blanco, Virginio Arias y Simón González en escultura; Pascual Ortega, Miguel Campos, Cosme San Martín, Pedro Carmona, Onofre Jarpa, Alfredo Valenzuela, José Mercedes Ortega, Enrique Lynch, Ernesto Molina y Nicanor González M., en pintura. De los segundos, los escultores Virginio Arias, Carlos Lagarrigue; los pintores Manuel Antonio Caro, Antonio Smith, Pedro Lira, Ramón Subercaseaux, Juan de Dios Vargas, José Tomás Errázuriz y Juan Francisco González.

La enumeración de los artistas es en razón a que dan cuenta de quienes circulan en el periodo, lo que le permitirá a Grez en el apartado siguiente (ocho) armar el canon, seleccionando algunos nombres y reproduciendo el modelo vasariano, describiendo tanto su biografía como alguna de sus obras más representativas. 
En resumen, el texto de Vicente Grez sobre la sección chilena para la Exposición Universal de París expone tanto el momento civilizador que vive el país en el ámbito de las bellas artes como su deseo de internacionalización y, en lo interno, se puede decir que se ha constituido el sistema de arte junto a la Academia, la circulación de obras -exposiciones-, la consolidación de la recepción de obras: por una parte la crítica de bellas artes de Grez y, por otra, la representada por José Miguel Blanco, Benjamín Vicuña Mackenna, Pedro Lira, Pedro Balmaceda; además de agregar al coleccionismo un incipiente mercado del arte.

Su conclusión resulta paradojal después de la valoración negativa que tiene de Alejandro Cicarelli ya que sus expresiones recuerdan el discurso de este:

En cuanto a aventurarse a presagiar acerca del futuro de la Escuela chilena, solo se puede formular con fundamento que tanto por los elementos de la raza como por la disposición del suelo y clima, el arte nacional siempre se consagrará más a la belleza del colorido y al sentimiento pintoresco que a la perfección del dibujo y a la pureza de la forma (Grez, Les beaux-arts au Chili).

\section{Conclusión}

El seguimiento de la obra de Grez en tanto cuadro de costumbre, posibilita al lector formarse una idea de época y cómo se va desarrollando la construcción del gusto desde la constitución de las instituciones de enseñanza, la circulación de la obra y su recepción.

La reconstrucción del recorrido de los textos analizados, en que Grez se hace cargo de las bellas artes desde fines del siglo XIX, se inicia con la fundación de la Academia de Pintura llegando hasta la participación del envío chileno a la Feria Universal de París de 1889, es decir, transcurren cuatro décadas de enseñanza artística en el país. De algún modo, con ello, Chile, busca ser reconocida como una nación civilizada y que da cuenta del progreso, alcanzado, como resultado, la reproducción de un modelo en la relación viejo mundo/nuevo mundo.

En lo interno, la producción escritural de Grez resume en sus distintas etapas la forma en que la prensa, en sus diferentes formatos, va recepcionando la actividad cultural y, en lo específico, las bellas artes; a este respecto, Grez representa los diferentes modelos textuales que se desarrollan: la crónica, la crítica y los estudios monográficos.

Por otra parte, el análisis realizado evidencia las vinculaciones de arte y política en el periodo, al darse una alianza natural entre la élite ilustrada y el gobierno, lo que va a ir determinando el gusto, el canon y los artistas que se ajustan al modelo académico.

Recuperar la obra de Grez en relación con su escritura sobre las bellas artes, completa zonas no documentadas y estudiadas de la historiografía del arte chileno, posibilitando una revisión fronteriza en lo disciplinar, por la actividad de quien se ocupa del estudio, ya que se reitera una metodología que resignifica la noción de la literatura artística al incorporar como fuente de documentación primaria el uso de textos provenientes de la literatura. 


\section{Referencias}

Cicarrelli, Alejandro. "Discurso Pronunciado en la inauguración de la Academia de Pintura por su director D. Alejandro Cicarreli”. Santiago: Imprenta Chilena, 1849. Medio impreso.

Grez, Vicente. Como en Santiago. Ed. Víctor Silva Castro. Santiago: Ediciones Universitarias, 1968. Medio impreso.

---. Antonio Smith (Historia del paisaje chileno). Santiago: Establecimiento tipográfico de La Época, 1882. Medio impreso.

---. Las bellas artes en Chile. Exposición Universal de París. Selección chilena. Santiago: Documento del Museo Nacional de Bellas Artes, 1889. Medio impreso.

Lira, Pedro. "Las Bellas Artes en Chile". Anales de la Universidad de Chile XXVIII, (1866): 276-92. Medio impreso.

Rodríguez, Hernán. “Exposiciones de arte en Santiago 1843-1887”. Formas de sociabilidad en Chile. Santiago: Vivaria (Fundación Mario Góngora), 1991. 279-314. Medio impreso.

Urquieta, Luis Álvarez. La pintura en Chile. Santiago: Imprenta La Ilustración, 1928. Medio impreso.

Valdés, Catalina. "Comienzo y deriva de un paisaje. Alessandro Cicarrelli, Antonio Smith y los historiadores del arte chileno". Dossier Thematique-imagen de la nation: Art et natura au Chili, Artelogie 3 (2012). <http://cral.in2p3.fr/artelogie/spip. php?article129>. Fecha de ingreso: 3 de julio 2013. Sitio web.

Vicuña Mackenna, Benjamín. "El arte nacional i su estadística ante la Exposición de 1884 (Revista Retrospectiva) 1858-1884". Enrique Solanich. Documentos de la Historia del Arte en Chile. Santiago: AICA, 2009. Medio impreso.

Silva Castro, Raúl. Vicente Grez (1847-1969). Santiago: Escritores de Chile VII, 1969. Medio impreso.

Zamorano, Pedro. Gestación de la escultura en Chile y la figura de Nicanor Plaza. Santiago: Artespacio, 2012. Medio impreso. 